\title{
CONTROLANDO AL GOBIERNO A TRAVÉS DE LAS URNAS. UN ANÁLISIS DEL CASO ARGENTINO ENTRE 1995 Y 2005
}

\author{
María Laura Tagina \\ marialaura.tagina@unsam.edu.ar \\ Universidad Nacional de San Martín \\ Universidad Nacional de La Matanza
}

Lo que hace posible la representación política es el hecho de que los gobiernos tengan que rendir cuentas periódicamente ante los ciudadanos; si éstos no están satisfechos con su desempeño pueden deshacerse de sus gobernantes en cada elección. No obstante en los últimos quince años el papel de las elecciones como mecanismo de accountability ha sido revisado, en particular para el caso de las democracias más jóvenes. Este artículo, utilizando datos de Latinobarómetro, analiza el caso de Argentina entre 1995 y 2005. Los resultados confirman la existencia de un voto retrospectivo a lo largo del periodo, con la excepción de los comicios de 1997, donde la mejora en las percepciones sobre el desempeño de la economía no hizo crecer las chances de voto por el oficialismo. En el artículo se ratifica que los factores que definieron el contexto general para cada elección mediaron en el impacto del voto retrospectivo en al menos en tres de los seis años electorales incluidos en el estudio.

Palabras clave: accountability, elecciones, voto retrospectivo, Argentina.

\section{CONTROLLING GOVERNMENT THROUGH THE BALLOT BOX: An ANALysis of the ARgentine CASE fROM 1995-2005}

What makes political representation possible is that governments must periodically be held to account. If voters are not satisfied with their performance they may use elections to rid themselves of political leaders. However in the last fifteen years the role of elections as mechanisms for accountability has been reexamined, particularly in young democracies. Using data from Latinobarometer, this article analyses the case of Argentina between 1995 and 2005. The results confirm the existence of a retrospective vote throughout the period, with the exception of the 1997 elections, wherein an improvement in public perceptions of economic performance did not increase chances for the incumbent. The article confirms that the factors which define the general context in each election affect the impact of retrospective vote in at least three of the six electoral years analysed.

Keywords: accountability, elections, retrospective vote, Argentina. 


\section{INTRODUCCIÓN ${ }^{1}$}

Lo que hace posible la representación política es el hecho de que los gobiernos tengan que rendir cuentas periódicamente ante los ciudadanos; si éstos no están satisfechos con su desempeño pueden deshacerse de sus gobernantes en cada elección. La elección es por lo tanto la principal institución del gobierno representativo (Manin 1999). Ello justifica la atención que las ciencias sociales han puesto sobre el comportamiento de los electores; en particular a partir de los años '40 del siglo XX, luego de la difusión del sufragio universal durante el período entreguerras ${ }^{2}$, se ha desarrollado una amplia literatura sobre este tema ${ }^{3}$.

No obstante en los últimos quince años el papel de las elecciones como mecanismo de accountability ha sido revisado. Se ha cuestionado su eficacia a la hora de desalojar a los gobernantes del poder producto de una mala gestión económica (Cheibub y Przeworski, 1996 y 1999). Se ha avanzado en la identificación de los factores políticos que favorecen o entorpecen la atribución de responsabilidad de los que gobiernan (Anderson, 2000 y 2005; Powell y Whitten, 2000; Samuels y Shugart, 2004; Samuels, 2005; Maravall, 2003 y 2008). Y se ha presentado a las elecciones como una instancia de selección que mira hacia el futuro, antes que como una mirada retrospectiva sobre la gestión de los que gobernaron (Fearon, 1999).

En el caso de las democracias más jóvenes se añaden a la vez dificultades específicas. La escasa estructuración de sus sistemas partidarios, la alta volatilidad de los votantes y los partidos, la pobre definición de los temas de la agenda pública y los cambios abruptos en la orientación de las políticas públicas, comprometería la efectividad de la accountability electoral en esos países (O’Donnell, 2007:87).

\footnotetext{
Una versión preliminar de este trabajo fue presentada en el XXI Congreso Mundial de Ciencia Política, ¿Descontento Global? Dilemas de cambio, Santiago de Chile, 12 al 16 de julio de 2009. La versión revisada se presentó en el Congreso 2010 de la Asociación de Estudios Latinoamericanos, Toronto, Canadá, del 6 al 9 de octubre de 2010. Agradezco a Lorena Schobert y a Ángel Camino Sánchez su valiosa colaboración para la realización de este trabajo.

2 No se desconoce que el derecho al sufragio universal es un proceso abierto inaugurado a fines del siglo XIX, extendido a las mujeres a mediados de siglo XX, y continuado en la actualidad con la extensión del voto a los ciudadanos que residen en el exterior y la incorporación de los extranjeros a distintas instancias de decisión electoral.

3 Las investigaciones pioneras de Lazarsfeld y sus colegas del Bureau de Ciencias Sociales Aplicadas de la Universidad de Columbia, son reconocidas como el punto de inicio de este campo de estudios.
} 
Como contrapeso, sin embargo, la literatura sobre comportamiento electoral da cuenta de una lenta declinación en los niveles de identificación partidaria en las democracias maduras y en América Latina, si bien se observa un movimiento en sentido contrario en España, Grecia y Portugal (Miller y Niemi, 2003; Moreno y Méndez, 2007; Sánchez, 2007). Dicho debilitamiento de las lealtades partidarias sumado a la incorporación progresiva de segmentos más jóvenes al cuerpo electoral reforzarían las chances de un voto de control retrospectivo.

Argentina se presenta entonces como un caso afectado por estas tendencias contradictorias ${ }^{4}$. Ha experimentado en los últimos tres lustros cambios en sus sistemas de partidos y altos niveles de volatilidad electoral y partidaria, además de giros bruscos en sus políticas públicas posibilitadas entre otros factores por la escasa definición de sus propuestas electorales, sumado a la pobre problematización en general de los temas que interesan a los ciudadanos. Y a la vez, ha registrado una declinación en el porcentaje de la población que afirma sentir cercanía por alguna fuerza política.

Resulta de interés por tanto verificar, a partir de datos individuales ${ }^{5}$, si en esta joven democracia las elecciones han funcionado como una instancia de control retrospectivo de los gobiernos, o si en cambio sus ciudadanos han votado principalmente en función de sus identificaciones de largo plazo, de su confianza en las instituciones $y$ aun de sus expectativas futuras, antes que del desempeño de quienes ejercieron el poder. Asimismo interesa indagar si en general los factores políticos que definieron el contexto de cada elección, mediaron en el impacto del voto retrospectivo por el oficialismo.

\section{MARCO TÉ́RICO}

El concepto de accountability o rendición de cuentas asociado a las elecciones remite a una forma de entender el voto como herramienta de control retrospectivo del

4 Este país representa un caso prototípico de la tercera ola de democratización en América Latina, con el colapso en 1982 del último régimen militar que gobernaba desde 1976, y las primeras elecciones libres celebradas en 1983.

5 Los trabajos revisionistas de Cheibub y Pzreworski (1996 y 1999), Samuels y Shugart (2004 y Samuels (2005), si bien incluyen a América Latina, han sido realizados sobre la base de datos agregados. El trabajo de Powell and Whitten (2000), también con datos agregados, no incluye en su muestra países latinoamericanos. Anderson (2000) refiere solo a sistemas parlamentarios. Gelinnau (2007) trabaja con datos de encuestas de opinión de Argentina, Brasil y Venezuela, pero analiza series temporales más breves, de tres elecciones para el caso de Argentina y Brasil, y cinco elecciones para el caso de Venezuela. 
gobierno. Tomado por la ciencia política del campo de la contabilidad, comprende en sí mismo al menos tres elementos; supone informar sobre las decisiones tomadas, dar una justificación de esas decisiones y someterse al juicio de un superior cuyo veredicto tiene un efecto concreto sobre el que rinde cuentas. Implica por lo tanto una relación de jerarquía entre el que evalúa y el que se somete a dicha evaluación.

Las elecciones son por tanto la institución fundamental del gobierno representativo. Son la forma de asegurar la sensibilidad de los representantes ante los intereses de los representados (Pitkin, 1967). En la medida que constituyen esa instancia de rendición de cuentas y control, operan como incentivo para que los gobiernos actúen de modo representativo. Si los ciudadanos utilizan su voto para confirmar al gobierno o desplazarlo del poder según éste haya actuado o no "in the best interest of the public", y si el gobierno anticipando esta reacción, intenta actuar de conformidad con las preferencias expresadas por los electores, entonces el mecanismo de accountability funciona. Por lo tanto, un gobierno es accountable si los ciudadanos pueden discernir entre gobiernos representativos y no representativos, y pueden sancionarlos apropiadamente manteniendo en el cargo a aquellos funcionarios electos que se desempeñaron bien y echando del poder a los que no. Ésta resulta ser entonces una relación entre resultados y sanciones (Manin et al. 1999).

Numerosas investigaciones en las últimas décadas procuraron indagar en qué medida las elecciones funcionan de este modo, arribando a resultados disímiles (Cheibub y Przeworski, 1999; Przeworski et al. 1999; Maravall, 2003; Samuels y Shugart, 2003; Samuels, 2004; Lewis-Beck 2000a, 2000b entre otros).

Los argumentos pesimistas son básicamente cuatro. El primero parte de la desigual distribución de información entre el gobierno y los votantes; los actos de gobierno son en su mayoría opacos ante la opinión pública y a la vez, los gobernantes manipulan la información puesta a disposición de los ciudadanos a fin de evadir la sanción de la urnas (Maravall, 2003). El segundo sostiene que las elecciones son ante todo una oportunidad para seleccionar buenos gobernantes. Por lo tanto antes que mirar al pasado, los electores votan prospectivamente eligiendo a los que evalúan en mejores condiciones de representar sus intereses (Fearon, 1999). El tercer argumento señala que las restricciones a la reelección presidencial cercenan las oportunidades de los ciudadanos de premiar o castigar al responsable principal de las políticas del gobierno, al tiempo que en los parlamentarismos los primeros ministros son a menudo reemplazados a partir de los cambios en la composición de la coalición de

6 Se retoma aquí la definición de representación de Pitkin (1967). 
gobierno, sin que esto guarde relación alguna con las preferencias expresadas por los votantes en las urnas (Cheibub y Przeworski, 1999). Un cuarto argumento refiere al rol que cumple la oposición en el mecanismo de accountability. Si la oposición está dividida y demasiado enfocada en sus luchas internas, o no tiene recursos institucionales para monitorear al gobierno, o negocia en secreto con quienes están en el poder (o siempre se opone y deja de ser cré́ble para el electorado), entonces deja de informar a los votantes y resta posibilidades de que éstos ejerzan su contralor electoral (Manin et al, 1999).

En cuanto a las investigaciones que respaldan la hipótesis del control retrospectivo del gobierno a través de las elecciones, las más recientes se enmarcan en la hipótesis del voto económico (Alvarez y Nagler 1994; Lewis-Beck 2000a, 2000b; Paldam y Nannestad 2000). También se encuentran aquellos trabajos que inscriptos en la corriente del neo institucionalismo empírico (de acuerdo a la clasificación de Peters 1999:121-146), analizan los factores estructurales que median en la atribución de responsabilidad al gobierno (Anderson, 2000; Samuels y Shugart, 2003; Samuels, 2004). En el caso de América Latina, un trabajo reciente de Murillo et al. (2009) confirma que el voto retrospectivo provee una explicación poderosa del reciente éxito electoral de la izquierda en la región.

\section{CONTEXTO POLÍTICO}

La década que se analiza está atravesada por cambios bruscos en la orientación general de las políticas, mediados por una crisis sin precedentes que tuvo repercusiones en el campo institucional, social y económico. Comprende el segundo gobierno del ex presidente justicialista Carlos Menem (1995-1999) ${ }^{7}$, devenido en uno de los principales exponentes del neoliberalismo en América Latina. La breve experiencia de la Alianza entre la Unión Cívica Radical y el Fre.Pa.So que culminó en 2001 con la crisis que puso fin al gobierno del entonces Presidente De la Rúa. La transición de dos años encabezada por otro justicialista, Eduardo Duhalde ${ }^{8}$. Y el inicio en 2003

\footnotetext{
El primero transcurre entre 1989 y 1995.
}

8 Duhalde, elegido por el Congreso de la Nación en enero de 2002 para completar el mandato aliancista, debió adelantar el llamado a elecciones debido al recrudecimiento de la protesta social. El 26 de junio de 2002 dos manifestantes piqueteros -Maximiliano Kosteki y Darío Santillán- fueron muertos por las fuerzas de seguridad de la Provincia de Buenos Aires cuando intentaban cortar el puente Pueyrredón, uno de los principales accesos desde el sur del conurbano bonaerense a la Capital Federal. En dicho operativo actuaban también, por orden del gobierno nacional, la Policía Federal, la Gendarmería y la Prefectura. http://edant.clarin.com/diario/2006/01/09/elpais/p-00601.htm 
del llamado "giro a la izquierda" encabezado por Néstor Kirchner, y sucedido en el poder cuatro años más tarde por su esposa, Cristina Fernández.

Probablemente el rasgo más particular para destacar de este período, por lo revelador que resulta de la idiosincrasia del sistema político argentino, sea que este movimiento pendular desde un gobierno con orientación neoliberal hacia otro enrolado en las nuevas izquierdas latinoamericanas, haya sido encabezado en ambos casos por el Justicialismo. Efectivamente, nueve de los once años que transcurren entre 1995 y 2005 corresponden a gobiernos de ese partido.

En total se celebraron tres elecciones presidenciales $(1995,1999$ y 2003) y seis elecciones de diputados nacionales (en esos mismos años, además de 1999, 2001 y 2005). Asimismo se realizaron elecciones de senadores nacionales en 1995, 1998, 2001, 2003 y 2005 . Hasta 2001 sin embargo, la elección de senadores estuvo a cargo de las Legislaturas provinciales, es decir, no se hizo por el voto directo de los ciudadanos.

Los diputados argentinos son elegidos por cuatro años y la Cámara se renueva por mitades cada dos. Los senadores son elegidos por seis años, y la Cámara se renueva por tercios cada bieño. El mandato presidencial es de cuatro años, y la reelección está autorizada constitucionalmente. Por lo tanto, el sistema de elecciones presidenciales y legislativas nacionales es parcialmente concurrente; la reforma constitucional de 1994 modificó el sistema electoral para la elección del Senado, y previó a través de disposiciones transitorias una puesta en vigencia progresiva de estas reformas (este rasgo del sistema electoral es compartido en América Latina únicamente por México, si bien en ese país la Cámara de Diputados se renueva en forma completa cada tres años, en tanto que el mandato presidencial es de seis años). 
Tabla $N^{\circ}$ 1: Fechas de elecciones y sondeos

\begin{tabular}{|c|c|c|c|c|}
\hline & Presidente & $\begin{array}{l}\text { Diputados } \\
\text { Nacionales }\end{array}$ & $\begin{array}{l}\text { Senadores } \\
\text { Nacionales }^{1}\end{array}$ & Encuesta \\
\hline 1995 & 14 de mayo & 14 de mayo & - & Mayo y junio \\
\hline 1997 & - & 26 de octubre & - & Diciembre \\
\hline 1999 & 24 de octubre & $\begin{array}{l}24 \text { de octubre y } \\
08 \text { de agosto, } \\
12 \text { y } 26 \text { de } \\
\text { septiembre }\end{array}$ & - & $\begin{array}{l}\text { Enero y } \\
\text { febrero de } 2000\end{array}$ \\
\hline 2001 & - & 14 de mayo & 14 de octubre ${ }^{2}$ & Abril y mayo \\
\hline 2003 & 27 de abril & $\begin{array}{l}27 \text { de abril } \\
14 \text { de septiembre } \\
26 \text { de octubre } \\
9 \text { de noviembre } \\
\end{array}$ & $\begin{array}{l}7 \text { de septiembre, } \\
5 \text { y } 26 \text { de octubre, } \\
9 \text { y } 23 \text { de } \\
\text { noviembre } \star \star \star\end{array}$ & Julio y agosto \\
\hline 2005 & - & 23 de octubre & 23 de octubre & $\begin{array}{l}\text { Agosto y } \\
\text { septiembre }\end{array}$ \\
\hline
\end{tabular}

FUENTE: Atlas electoral de Andy Tow y reporte ficha técnica de Latinobarómetro.

En 1995 se eligió un tercio del Senado por vía de las legislaturas provinciales y se agregó un tercer senador por provincia, de acuerdo a la disposición transitoria cuarta de la Constitución sancionada en 1994. En 1998 se eligió nuevamente un tercio del Senado, siguiendo aún el procedimiento indirecto fijado por la antigua Constitución.

2 Se renovó la totalidad del senado, según la disposición transitoria quinta de la Constitución sancionada en 1994.

* - Misiones, Catamarca, San Luis, Neuquén, Tierra del Fuego

** 27-04 (Santiago del Estero, La Rioja); 14-09 (Bs As, Chaco, Jujuy, Santa Cruz); 26-10 (Catamarca, La Pampa, Mendoza, Tucumán); 09-11 (Chubut)

***-Catamarca, Chubut, Córdoba, Corrientes, La Pampa, Mendoza, Santa Fé, Tucumán

En lo que hace a su sistema de partidos, Argentina mostró un comportamiento errático a lo largo de este período. Los resultados de las tres elecciones presidenciales permiten ubicarlo sucesivamente en puntos diferentes de una escala que va del bipartidismo al pluralismo extremo. Así en 1995, con 3,18 partidos electorales, el sistema de partidos argentino se correspondía con un pluralismo limitado, mientras que en 1999 con 2,55 partidos, se situaba en torno a valores bipartidistas, convirtiéndose en 2003, con 5,66 partidos, en un pluralismo extremo (Alcántara, 1996). En 2007 el número efectivo de partidos se estabiliza en torno de los valores de 1995, alcanzando 3,41 partidos, si bien esta elección no es considerada en el presente análisis. 


\section{Gráfico $N^{\circ} 1$}

Número efectivo de Partidos Presidenciales

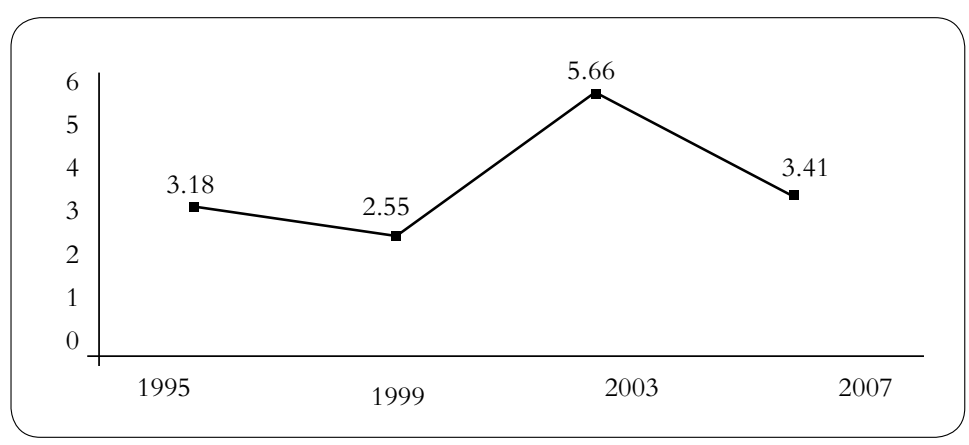

Fuente: Elaboración propia a partir de datos del Atlas Electoral de Andy Tow

En el caso de la Cámara de Diputados, el número efectivo de partidos legislativos creció desde 2,86 en 1993-1995 hasta un máximo de 4,16 en 2005-2007.

Gráfico $N^{\circ} 2$

Número efectivo de Partidos Legislativos

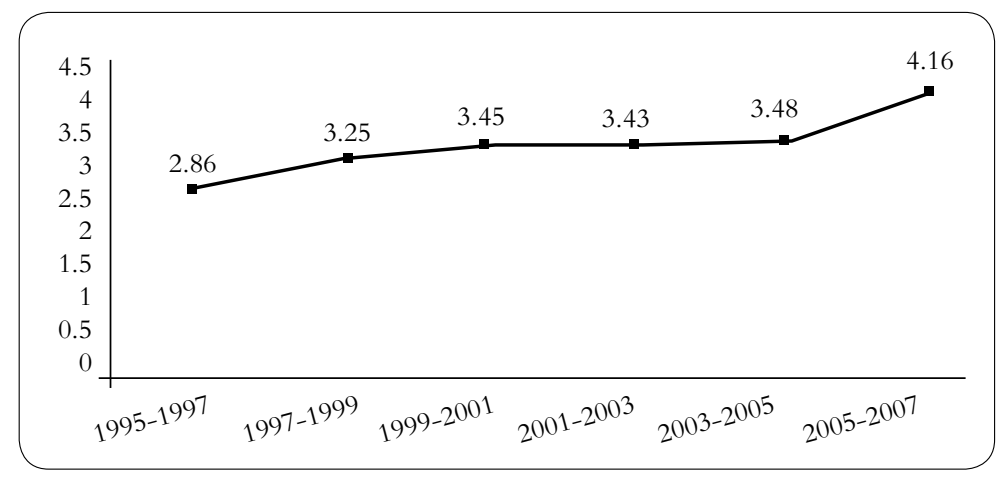

Fuente: Elaboración propia a partir de datos de Legislatina, OIR, Universidad de Salamanca 
En cuanto a la volatilidad electoral ${ }^{9}$, la complejidad que supuso la elaboración de este cálculo para el caso argentino da cuenta de la particular dinámica de su sistema de partidos. El elevado número de fuerzas políticas que participa en las elecciones, la constitución de sucesivas alianzas y frentes electorales que desaparecen en la siguiente contienda, la vida efimera de los partidos que surgen en torno de figuras políticas y desaparecen junto con ellas de las escena política son algunos de sus principales rasgos. Así, comparando los resultados de 1995 y 1999 la volatilidad en elecciones presidenciales fue de 28 puntos, en tanto que entre 1999 y 2003 trepó a 51 puntos, para volver a caer en el comparativo de 2003 y 2007 a 25 puntos.

\section{Gráfico $\mathrm{N}^{\circ} 3$}

Volatilidad elecciones presidenciales

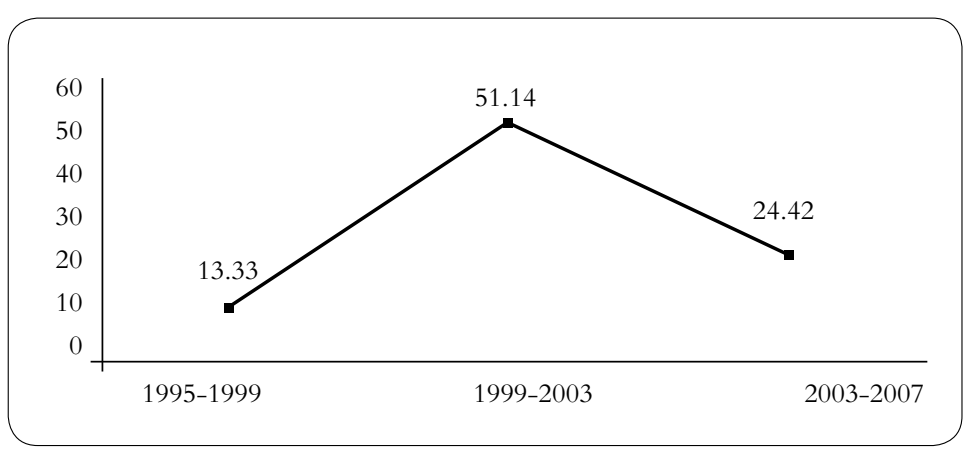

Fuente: Elaboración propia a partir de datos del Atlas Electoral de Andy Tow

Por su parte la volatilidad legislativa alcanza su máximo nivel cuando se compara la distribución de escaños de la legislatura de 1999-2001 con la de 2001 y 2003.

9 La volatilidad de los votos está referida a los cambios agregados en dos elecciones sucesivas y que se deben a transferencias individuales de votos (Montero, 1992) y que están vinculados tanto a su orientación como a la competitividad inter-partidaria (Alcántara, 1997). En este caso, se compararon los resultados electorales por alianza de partidos que apoyaban una misma fórmula presidencial en dos elecciones sucesivas, y se tomó como referencia al partido que encabezaba cada coalición. 


\section{Gráfico $\mathrm{N}^{\circ} 4$}

Volatilidad Legislativa

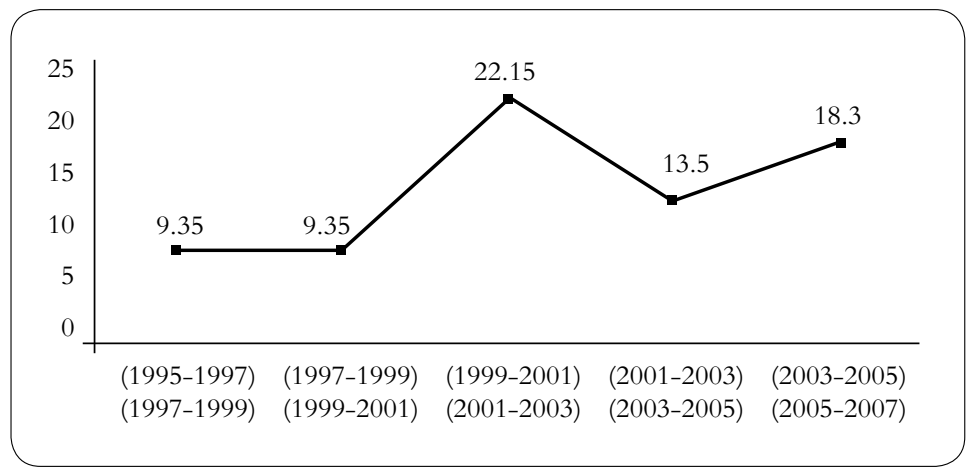

Fuente: Elaboración propia a partir de datos de Legislatina, OIR, Universidad de Salamanca

En lo que hace a la identificación partidaria, si bien constituye un atributo de los individuos antes que del contexto, su evolución en el período de análisis resulta reveladora del clima político. Así, los niveles de identificación con los partidos políticos revelados por los entrevistados han disminuido en forma sistemática entre 1995 y $2003^{10}$, variando entre un $38 \%$ y un $23 \%$. Es decir que en sólo siete años, un 15\% de la población dejó de sentirse próxima o simpatizante de alguna fuerza política.

Gráfico $N^{\circ} 5$

Identificación Partidaria

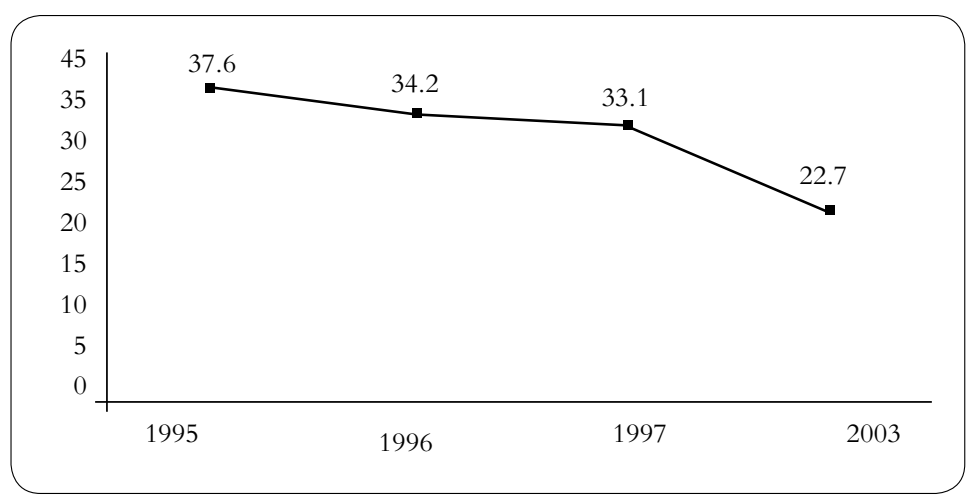

Fuente: Latinobarómetro

10 La pregunta sobre identificación partidaria fue incluida solo en cuatro de los diez relevamientos que se analizan, correspondientes a los años 1995, 1996, 1997 y 2003. 
El tamaño del bloque de diputados y senadores del partido del presidente es otro de los rasgos relevantes del contexto político, que impacta además en las condiciones de gobernabilidad del sistema político. Durante la década que se analiza lo más habitual ha sido que el bloque de diputados oficialistas constituya la primera minoría en la Cámara de Diputados, con la sola excepción de 1995 a 1997, en las que controló más del 50\% de las bancas. Esta situación se reiteró a partir de 2005. La situación en el Senado ha sido distinta. En este caso el oficialismo controló siempre la mayoría absoluta de la bancas, a excepción del breve período de gobierno de la Alianza.

Ambas situaciones se explican por el sistema electoral. Por un lado la renovación por mitades de la Cámara de Diputados implica que aun una contundente victoria por parte del partido del Presidente en una elección concurrente (presidencial y legislativa) impacte sólo parcialmente en la composición de la cámara baja. A ello se suma que en las elecciones intermedias, luego de dos años de gestión, el partido del presidente suele obtener un apoyo menor. En cuanto al Senado, hasta 2001 sus integrantes fueron elegidos por las Legislaturas provinciales, tradicionalmente dominadas por el Justicialismo. Como ya se señaló, esta situación cambió a partir la reforma constitucional de 1994, si bien el nuevo artículo 54 que fija la forma directa de elección de los senadores entró en vigencia recién a partir de 2001.

Otra característica del contexto político ha sido el predominio de gobiernos monopartidistas, por encima de gobiernos de alianza. A diferencia de otros países latinoamericanos (Brasil y Panamá entre otros), no es tradición en Argentina repartir los puestos del gabinete entre las fuerzas políticas que pudieron haber acompañado la fórmula presidencial. 
Tabla $N^{\circ} 2$

Elementos del contexto político según año de realización de la encuesta

\begin{tabular}{|c|c|c|c|c|c|c|}
\hline & 1995 & 1997 & 2000 & 2001 & 2003 & 2005 \\
\hline $\begin{array}{l}\text { Partido de Go- } \\
\text { bierno al mo- } \\
\text { mento de reali- } \\
\text { zarse la encuesta }\end{array}$ & $\begin{array}{l}\text { Justi- } \\
\text { cialista }\end{array}$ & $\begin{array}{l}\text { Justi- } \\
\text { cialista }\end{array}$ & $\begin{array}{l}\text { Alianza } \\
\text { UCR- } \\
\text { Fre.Pa.So }\end{array}$ & $\begin{array}{l}\text { Alianza } \\
\text { UCR- } \\
\text { Fre.Pa.So }\end{array}$ & $\begin{array}{l}\text { Justi- } \\
\text { cialista }\end{array}$ & $\begin{array}{l}\text { Justi- } \\
\text { cialista }\end{array}$ \\
\hline $\begin{array}{l}\% \text { y } \mathrm{n}^{\circ} \text { escaños } \\
\text { del partido de } \\
\text { gobierno } \\
\text { en Diputados }\end{array}$ & $\begin{array}{c}48,2^{1} \\
(124 \mathrm{esc})\end{array}$ & $\begin{array}{c}51,4^{2} \\
(132 \text { esc) }\end{array}$ & $\begin{array}{c}46,7^{3} \\
(120 \text { esc) }\end{array}$ & $\begin{array}{c}39,7^{4} \\
(102 \text { esc) }\end{array}$ & $\begin{array}{c}34,2^{5} \\
(88 \text { esc) }\end{array}$ & $\begin{array}{c}50,2^{6} \\
(129 \text { esc) }\end{array}$ \\
\hline $\begin{array}{l}\% \text { y n }{ }^{\circ} \text { escaños } \\
\text { del partido de } \\
\text { gobierno en el } \\
\text { Senado }\end{array}$ & $\begin{array}{c}54,2^{a} \\
(39 \mathrm{esc})\end{array}$ & $\begin{array}{c}54,2^{\mathrm{a}} \\
(39 \mathrm{esc})\end{array}$ & $\begin{array}{l}27,8 \%^{\mathrm{b}} \\
(20 \mathrm{esc})\end{array}$ & $\begin{array}{c}27,8^{c} \\
(20 \mathrm{esc})\end{array}$ & $\begin{array}{c}55,5^{\mathrm{d}} \\
(40 \mathrm{esc})\end{array}$ & $\begin{array}{c}52,8^{\mathrm{e}} \\
(38 \mathrm{esc})\end{array}$ \\
\hline $\begin{array}{l}\text { Situación del par- } \\
\text { tido de gobierno } \\
\text { en el Congreso }\end{array}$ & $\begin{array}{c}\text { minori- } \\
\text { tario }\end{array}$ & $\begin{array}{c}\text { mayori- } \\
\text { tario }\end{array}$ & $\begin{array}{c}\text { minori- } \\
\text { tario }\end{array}$ & $\begin{array}{c}\text { minori- } \\
\text { tario }\end{array}$ & $\begin{array}{c}\text { minori- } \\
\text { tario }\end{array}$ & $\begin{array}{c}\text { mayori- } \\
\text { tario }\end{array}$ \\
\hline $\begin{array}{l}\text { NEP } \\
\text { legislativo } \star \star \star\end{array}$ & 2,86 & 2,86 & 3,25 & 3,45 & 3,43 & 3,48 \\
\hline $\begin{array}{l}\text { Tipo de } \\
\text { Gobierno }\end{array}$ & $\begin{array}{c}\text { mono } \\
\text { partidista }\end{array}$ & $\begin{array}{c}\text { mono } \\
\text { partidista }\end{array}$ & coalición & coalición & $\begin{array}{c}\text { mono } \\
\text { partidista }\end{array}$ & $\begin{array}{c}\text { mono } \\
\text { partidista }\end{array}$ \\
\hline
\end{tabular}

Fuente: Los datos sobre porcentaje y número de escaños fueron tomados de Legislatina, Observatorio del Poder Legislativo en América Latina, Universidad de Salamanca y del Observatorio Electoral. Los datos sobre NEP son elaboración propia a partir de esas mismas fuentes.

* Se considera el total de escaños del partido de gobierno al momento de realizarse la encuesta.

1 Corresponde a los escaños del bloque Justicialista elegidos en 1993-1995.

2 Corresponde a los escaños del bloque Justicialista elegidos en 1995-1997.

3 Corresponde a los escaños del bloque Justicialista elegidos en 1997-1999.

4 Corresponde a los escaños del bloque de la Alianza elegidos en 1999-2001.

5 Corresponde a los escaños del bloque de la Alianza elegidos en 2001-2003.

6 Corresponde a los escaños del bloque Justicialista elegidos en 2003-2005.

a Corresponde a los escaños del bloque Justicialista elegidos en 1989-1995.

b Corresponde a los escaños de los bloques UCR + FREPASO elegidos en 1989-1995.

Corresponde a los escaños de los bloques UCR + FREPASO elegidos en 2001.

d Corresponde a los escaños del bloque Justicialista elegidos en 2001-2003.

e Corresponde a los escaños del bloque Justicialista elegidos en 2001-2003-2005.

** Se define como "gobierno mayoritario" a aquel en el que el partido del Presidente controla la mayoría absoluta de ambas Cámaras.

*** base 257 diputados. 


\section{DATOS, HIPÓTESIS PRELIMINARES Y METODOLOGÍA}

Los datos que se analizan corresponden a diez encuestas de Latinobarómetro, realizadas entre 1995 y 2005 en Argentina. Las mismas fueron fusionadas en una única base de datos de 11.995 casos. Para el análisis se utilizan técnicas de regresión logística binaria, con estandarización de variables y términos interactivos.

La variable dependiente, definida como voto por el oficialismo, fue creada a partir de una trabajosa recodificación de la intención de voto -o el voto efectivodeclarados en cada encuesta, dada la alta volatilidad de los votantes y los partidos en Argentina ${ }^{11}$. A ello se suma que a lo largo de una década distintas coaliciones partidarias se turnaron en el poder. En todos los casos, se asignó 1 = voto por el partido oficialista (o coalición oficialista) y $0=$ voto por el resto de los partidos.

El control retrospectivo del gobierno fue medido a partir del coeficiente de regresión arrojado por la variable evaluaciones económicas retrospectivas. A modo de control, se introdujeron como variables independientes las evaluaciones económicas prospectivas, la auto ubicación ideológica, la identificación partidaria, el compromiso religioso, la confianza en el Presidente, la confianza en el gobierno, la confianza en el Congreso, el nivel educativo del entrevistado, su edad y sexo.

En cuanto al contexto político, la multiplicidad y la concurrencia de los factores que lo definen imponen ciertas restricciones a la hora de captar su impacto en el voto. Las variaciones en las características del sistema de partidos, del tamaño del bloque oficialista en cada una de las Cámaras del Poder legislativo, la etiqueta del partido que está en el gobierno y el tipo de gobierno, ofrecen distintas combinaciones posibles en cada elección. La posibilidad por lo tanto de distinguir los efectos de una característica contextual de la otra, requiere de una variabilidad longitudinal que excede largamente las seis elecciones que aquí se analizan (hay muchas más combinaciones posibles de estas variables contextuales que elecciones). Por ejemplo, entre 1995 y 2005 no hay casos de elecciones con gobiernos mayoritarios y de coalición, o de gobiernos no Justicialistas y mayoritarios. Por tal motivo se escogió la estrategia de considerar cada contexto en su conjunto, creando variables dummy para cada uno de los años en que se celebraron elecciones.

11 A modo de ejemplo, en 1999 gana las elecciones presidenciales la Alianza para la Educación y el Progreso, una coalición partidaria que agrupa a la Unión Cívica Radical y al Frepaso. Cada uno de esos partidos sin embargo, presentó formulas presidenciales diferentes en 1995. Y en 2003, el FREPASO no compitió en las elecciones presidenciales, en tanto que la UCR integró una fórmula con un candidato peronista. 
Tabla $\mathrm{N}^{\circ} 3$

Distribución de la intención de voto frecuencias en porcentajes

\begin{tabular}{|c|c|c|c|c|c|c|}
\hline Partidos & 1995 & 1997 & 2000 & 2001 & 2003 & 2005 \\
\hline No responde & 10,6 & 4,3 & 6,2 & 5,4 & 1,9 & 4,3 \\
\hline Ninguno & & & 10,2 & & & \\
\hline No vota & & & 1,3 & & & \\
\hline Vota por personas no por partidos & & & 1 & & & \\
\hline Otros & & 5,6 & 0,1 & 0,8 & 1,1 & 3,9 \\
\hline Voto nulo/ voto en blanco & & & 4,4 & 15,8 & 5,8 & 7,5 \\
\hline No vota/ninguno & & & & 26,2 & 16,8 & 17,4 \\
\hline No inscripto & & & & 0,3 & 0,6 & 0,4 \\
\hline No sabe & 30,3 & 21,7 & 19,9 & 24,1 & 29.8 & 28,7 \\
\hline Ninguno/No Aplica & & 15,2 & 10,2 & & & \\
\hline Partido Justicialista & 25,7 & 11,3 & 18,5 & 12 & 30,1 & 28,2 \\
\hline Unión Cívica Radical & 11,7 & 24,7 & 9,6 & 5,7 & 4,6 & 4,3 \\
\hline Frente País Solidario & 19,2 & 12,5 & 0,4 & 1,3 & & \\
\hline ALIANZA UCR - Fre.Pa.So & 3,6 & 4,5 & 24,1 & 3,6 & & \\
\hline Recrear Argentina & & & & & 1,8 & 0,6 \\
\hline Afirmación para una República Igualitaria & & & & & 2,4 & 2,4 \\
\hline Compromiso para el Cambio & & & & & & 0,2 \\
\hline Izquierda Unida & & & & 0,7 & 1,8 & 0,1 \\
\hline Partido Socialista & & & & & 1,2 & 1,8 \\
\hline Partido Obrero & & & & 0,4 & 0,1 & \\
\hline Autodeterminación y Libertad & & & & & & 0,3 \\
\hline Partido Humanista & & & 2 & & & \\
\hline \multicolumn{7}{|l|}{ Partido Comunista } \\
\hline Movimiento al Socialismo & 0,7 & & & & & \\
\hline Alianza Sur & 0,1 & & & & & \\
\hline Unión de Centro Democrático & 0,2 & & & & & \\
\hline Acción por la República & & & 2,1 & 2,3 & & \\
\hline Nueva Dirigencia & & & 0,3 & & & \\
\hline \multicolumn{7}{|l|}{ Partido Demócrata } \\
\hline Movimiento por la Dignidad y la Indendencia & 1,1 & & & & & \\
\hline Fuerza Republicana & 0,1 & & & & & \\
\hline Partido Federal & 0,2 & & & & & \\
\hline Partido Independencia & 0,1 & & & & & \\
\hline Demócrata Progresista & 0,2 & & & & & \\
\hline \multicolumn{7}{|l|}{ Unión por Córdoba } \\
\hline Otros partidos nacionales & & & & 1,3 & 0,8 & \\
\hline Partidos Provinciales & & & & 0,3 & & \\
\hline Otros Partidos Provinciales & & & & & 1,3 & \\
\hline 4to Partido de oposición & & 0,1 & & & & \\
\hline $\mathrm{n}=$ & 1200 & 1196 & 1200 & 1200 & 1200 & 1200 \\
\hline
\end{tabular}

Fuente: Latinobarómetro 
Dada la naturaleza dicotómica de la variable dependiente, la existencia e intensidad del voto de control retrospectivo se midió por medio de ecuaciones de regresión logística binomial. Un coeficiente positivo y estadísticamente significativo de las percepciones económicas retrospectivas, indica que la intención de voto por el oficialismo estuvo vinculada a una evaluación positiva de su gestión en materia económica. En el mismo sentido, un coeficiente positivo y con significación estadística de la variable dummy correspondiente a un determinado año electoral indica que el contexto político de ese año electoral, mantenidos constantes el resto de los factores, contribuyó con las probabilidades de un voto a favor del oficialismo, comparando con el resto de los años considerados en el análisis. Un coeficiente significativo y negativo en cambio, indicaría que el contexto de ese año influyó negativamente.

La hipótesis que guió el análisis indica que la relación entre percepciones económicas pasadas y voto por el oficialismo está moderada por el contexto propio del año en que se evalúa dicha relación. Esto es:

$H_{1}$ : El impacto de las evaluaciones económicas retrospectivas en el voto al oficialismo varía según el contexto político de cada elección.

Y la hipótesis nula:

H0: El impacto de las evaluaciones económicas retrospectivas en el voto al oficialismo no varía según el contexto político de cada elección.

Para testearla se introdujeron términos de interacción entre economía retrospectiva y cada uno de los años electorales. Una interacción estadísticamente significativa indica en principio que la relación entre voto económico retrospectivo y voto por el oficialismo es contingente al contexto del año en que se mide la relación. El coeficiente positivo de la interacción indicaría que el efecto de las percepciones económicas retrospectivas sobre las probabilidades de apoyo al oficialismo crecen para el año electoral específico que se analiza en la interacción, con respecto al resto de los años contemplados en el análisis. En otras palabras, que las particulares características del contexto del año analizado en la interacción hace aumentar las chances de un voto influido por las percepciones del desempeño económico del gobierno.

La incorporación de interacciones al análisis de regresión logística ha sido recientemente problematizado por la literatura (Jaccard et al. 1990; Brambor et al. 2006; Hayes, Metthes 2009). En todos los casos se pone énfasis en las dificultades que ofrece interpretar correctamente el coeficiente de regresión de las interacciones así 
como los coeficientes de las variables que componen el término interactivo, individualmente consideradas. Por su parte Hayes (2009) enfatiza la necesidad de estimar el efecto de la variable independiente (también llamada predictora o focal) sobre la dependiente, en presencia de los distintos valores que asume la variable moderadora (es decir, la segunda del término interactivo). A la vez recuerda que este análisis es raras veces realizado por los investigadores, entre otros motivos porque los programas estadísticos de uso habitual no calculan dichos coeficientes (2009: 925). En particular recomienda la técnica de Johnson-Neymann $(\mathrm{J}-\mathrm{N})$, que identifica regiones en el rango de categorías de la variable moderadora en las cuales el efecto de la variable predictora sobre la variable dependiente es estadísticamente significativo, y aquellas en los que no lo es. El mismo Hayes ha creado un macro y un script que puede utilizarse con SPSS que aplica la técnica de J-N $\mathrm{N}^{12}$ y que fue utilizado en esta investigación.

En cuanto al objetivo de verificar si las elecciones han funcionado principalmente como una instancia de control retrospectivo de los gobiernos o si en cambio, los ciudadanos han votado en función de sus identificaciones, de su confianza institucional y/o de sus expectativas futuras, el mismo se aborda con carácter exploratorio.

\section{ANÁLISIS}

El primer paso consistió en analizar la evolución del voto por el oficialismo y las percepciones económicas retrospectivas. Por medio de un gráfico de curvas se comparó el recorrido de ambas variables entre 1995 y 2005. En el caso de la economía se seleccionaron las opiniones de quienes respondieron que "la economía está mejor que hace un año atrás".

12 Puede accederse on line a través de este link http://www.comm.ohio-state.edu/ahayes/SPSS $\% 20$ programs/modprobe.htm

MODPROBE is an computational aide for SAS and SPSS for probing single-degree-of-freedom interactions in OLS and logistic regression. It estimates model coefficients and standard errors for a model estimating an outcome variable from a focal predictor variable, a proposed moderator variable, the product of the focal and predictor variable, and any additional variables used as statistical controls. The outcome can be quantitative, in which case the model is estimated using OLS regression, or binary, in which case the model is estimated using logistic regression. The macro will detect whether or not the outcome is binary and estimate appropriately without additional user input. In addition to estimating the coefficients of the model, it produces tests of the conditional effect of the focal predictor on the outcome at values of the moderator, also called simple slopes. BY default, conditional effects of the focal predictor are estimated at the sample mean of the moderator variable as well as one standard deviation above and below the sample, unless the moderator variable is dichotomous, in which case it produces conditional effects of the focal predictor at the two values of the moderator variable. 
El apoyo al partido de gobierno se mantiene muy por encima de las evaluaciones económicas retrospectivas a lo largo de toda década. La medición más baja se registra en 1997, para las elecciones de medio término del segundo gobierno de Carlos Menem, con un 19,2\% de la intención de voto en tanto que la más alta se da en 2004, primer año cumplido de la gestión kirchnerista, con un 69\% de apoyo. La mayor distancia entre ambas variables se da en 2000, inmediatamente después de la asunción del gobierno de la Alianza, cuando las evaluaciones retrospectivas de la economía continúan cayendo, en tanto que el apoyo al gobierno trepa al 61\%, continuando con el incremento registrado a partir de 1998.

Economía retrospectiva y voto muestran una tendencia semejante recién a partir de 2003, cuando la mejora en las percepciones económicas es acompañada por un incremento en el apoyo al oficialismo. Es justamente en el año 2003 cuando se registra una caída abrupta en los niveles de identificación partidaria, según se mostró en el Gráfico n 5 . Entre 1995 y 2002 sin embargo, percepciones económicas y apoyo al oficialismo difieren en su comportamiento. Así en tanto las evaluaciones positivas respecto del estado de la economía oscilan entre un $11,8 \%$ y un $6,5 \%$ con una tendencia mayormente declinante, el apoyo al gobierno registra cambios abruptos.

\section{Gráfico $N^{\circ} 6$}

Evaluaciones económicas retrospectivas y voto por el oficialismo

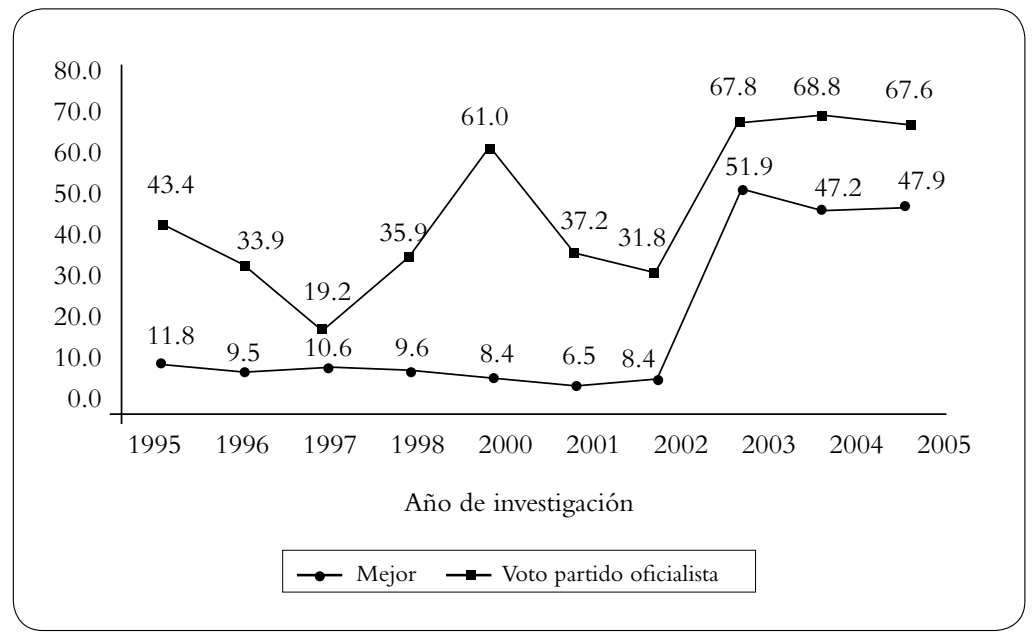

Fuente: Elaboración propia a partir de datos de Latinobarómetro 


\subsection{Explorando el voto retrospectivo}

El siguiente paso en pos de testear la existencia de un voto de control retrospectivo entre los votantes argentinos, consistió en calcular la pendiente de la curva de regresión $\beta$ de la variable retrospectiva, en diferentes modelos de voto. En cada modelo, se comparó además su impacto con el del resto de las variables independientes; para ello se estandarizó cada una de estas variables.

El análisis de regresión reveló la existencia de un voto de control retrospectivo durante la década que se analiza. Ello implica que los ciudadanos argentinos tomaron en consideración el desempeño económico del gobierno a la hora de decidir su voto. Sin embargo las evaluaciones económicas prospectivas tuvieron una mayor influencia. Esto es, las expectativas positivas sobre la marcha futura de la situación económica del país presentan una correlación mayor con el voto por el oficialismo, que las evaluaciones favorables acerca del desempeño pasado. Estos datos confirmarían para el caso argentino la observación de Fearon (1999) cuando señala que el voto es una opción hacia el futuro antes que una reacción al desempeño pasado del gobierno.

Por su parte la ideología también presenta un impacto positivo en el apoyo al oficialismo; esto significa que en promedio entre 1995 y 2005, las chances de apoyo crecen a medida que los electores se desplazan hacia la derecha en la escala ideológica, si bien distintos partidos se alternaron en el poder durante este período.

En cuanto a la confianza institucional, también aparece asociada al voto por el partido en el gobierno. La confianza en el Congreso se asocia negativamente; esto es, el apoyo al oficialismo crece cuando disminuye la confianza en el parlamento. Ello podría interpretarse como un reflejo de la situación de gobierno dividido (minoritario), que ha sido la preeminente a lo largo del período que se estudia ${ }^{13}$. Por el contrario, la confianza en el Presidente se revela como un factor de gran peso a la hora de predecir el voto por oficialismo. Cuando se reemplaza dicha variable por la confianza en el Gobierno (Ecuación 2), la confianza en el Congreso pierde significación estadística, quedando su influencia diluida, a la vez que crece el porcentaje de variabilidad del voto por el oficialismo explicada por el modelo $\left(\mathrm{R}_{2}\right.$ Cox y Snell $=.23 \mathrm{y} \mathrm{R}_{2}$ Nagerkelke =.306). En cuanto a las variables de control, no alcanzan significación estadística en presencia de Compromiso Religioso (Ecuación 1). Sin

13 Según se mostró en la Tabla n 2, el partido en el gobierno sólo contó con mayoría absoluta en ambas Cámaras legislativas entre 1995 y 1997 y a partir de 2005. 
embargo cuando se omite esa variable, se observa que a menor educación y menor edad, mayor apoyo al partido en el gobierno (Ecuaciones 2 y 3).

En términos comparados, la confianza en el gobierno y en el presidente aparecen como las mejores predictoras del apoyo al partido oficialista, muy por encima del desempeño económico del gobierno y aun de las expectativas futuras sobre la evolución de la economía. Una percepción positiva sobre el desempeño del gobierno en materia económica no surge como definitoria del apoyo al oficialismo a lo largo de esta década, así como una percepción negativa no implica necesariamente su castigo.

Tabla $N^{\circ} 4$

Regresiones logísticas binomiales con variables estandarizadas

\begin{tabular}{|c|c|c|c|}
\hline & Ecuación 1 & Ecuación 2 & Ecuación 3 \\
\hline $\begin{array}{l}\text { Var. Dep.: } \\
\text { Voto por el oficialismo }\end{array}$ & Coef. B & Coef. B & Coef. B \\
\hline Economía País Retrospectiva & $\begin{array}{c}208 \star \star \star \\
(, 058)\end{array}$ & $\begin{array}{c}293 \star \star \star \\
(, 049)\end{array}$ & $\begin{array}{c}, 297 \star \star \star \\
(, 048)\end{array}$ \\
\hline Economía País Futura & $\begin{array}{c}, 285 \star \star \star \\
(, 061) \\
\end{array}$ & $\begin{array}{c}, 373 \star \star \star \\
(, 056)\end{array}$ & $\begin{array}{c}, 366^{\star \star \star} \\
(, 055)\end{array}$ \\
\hline Ideología & $\begin{array}{l}, 089 \star \\
(, 052)\end{array}$ & $\begin{array}{c}252 \star \star \star \\
(, 048)\end{array}$ & $\begin{array}{c}251 \star \star \star \\
(, 048)\end{array}$ \\
\hline Compromiso Religioso & $\begin{array}{l}-, 064 \\
(, 056)\end{array}$ & & \\
\hline Confianza Presidente & $\begin{array}{c}, 757 \star \star \star \\
(, 065) \\
\end{array}$ & & \\
\hline Confianza Gobierno & - & $\begin{array}{c}, 658 \star \star \star \\
(, 058) \\
\end{array}$ & $\begin{array}{c}, 628 \star \star \star \\
(, 052) \\
\end{array}$ \\
\hline Confianza Congreso & $\begin{array}{c}-, 187 \star \star \\
(, 057) \\
\end{array}$ & $\begin{array}{l}-, 069 \\
(, 053) \\
\end{array}$ & \\
\hline Confianza Interpersonal & $\begin{array}{l}, 013 \\
(, 054)\end{array}$ & & \\
\hline Educación & $\begin{array}{l}-, 062 \\
(, 055)\end{array}$ & $\begin{array}{c}-, 317 \star \star \star \\
(, 053)\end{array}$ & $\begin{array}{c}-, 319 \star \star \star \\
(, 052)\end{array}$ \\
\hline Edad & $\begin{array}{l}-, 078 \\
(, 058) \\
\end{array}$ & $\begin{array}{c}-, 219 \star \star \star \\
(, 053)\end{array}$ & $\begin{array}{c}-, 212 \star \star \star \\
(, 052)\end{array}$ \\
\hline Sexo & $\begin{array}{l}, 041 \\
(, 054) \\
\end{array}$ & $\begin{array}{l}-, 012 \\
(, 049) \\
\end{array}$ & $\begin{array}{l}-, 018 \\
(, 048) \\
\end{array}$ \\
\hline _cons & $\begin{array}{l}-, 038 \\
(, 057) \\
\end{array}$ & $\begin{array}{l}-, 128^{\star} \\
(, 052)\end{array}$ & $\begin{array}{c}-, 143 \star \star \\
(, 052) \\
\end{array}$ \\
\hline $\mathrm{N}$ & 1783 & 2247 & 2290 \\
\hline Sig. Chi-cuadrado &, 000 &, 000 &, 000 \\
\hline R2 de Cox y Snell &, 18 &, 23 & ,227 \\
\hline R2 de Nagerkelke & ,242 & ,306 & ,303 \\
\hline
\end{tabular}




\section{La mediación del contexto político ${ }^{14}$}

Dada la relevancia que la teoría de la democracia otorga a la función de accountability de las elecciones, el segundo objetivo de este trabajo consistió en conocer en qué medida la presencia de un voto de control retrospectivo del gobierno pudo haber variado de elección en elección producto del contexto político en que cada una de ellas se celebró. La opción escogida fue la de calcular las interacciones entre el voto retrospectivo y el año electoral. Como ya se señaló, la presunción de la que se parte es que la relación entre percepciones económicas retrospectivas $\left(\mathrm{X}_{1}\right)$ y voto por el oficialismo $(\mathrm{Y})$ está moderada por un tercer factor $\left(\mathrm{Z}_{2}\right)$ : el contexto propio del año en que se evalúa dicha relación. En otras palabras, se presupone que la relación entre economía y voto varía dependiendo de las características del contexto del año que se considere en el análisis. La inclusión de estas interacciones en la ecuación de voto permiten además interpretar si ese impacto fue positivo o negativo, es decir, si comparando el año en cuestión con el resto de los años en que se realizaron las entrevistas, el peso del voto de control retrospectivo fue mayor o menor. El modelo de voto quedaría expresado de este modo:

$$
Y=\alpha+\beta_{1} X_{1}+\beta_{2} Z+\beta_{3} X_{1} Z+\beta_{4} X_{2}+\varepsilon
$$

Donde $\boldsymbol{\alpha}$ es la constante, $\mathrm{X}_{1}$ es Economía Retrospectiva, $\mathrm{Z}$ es el Año Electoral, $\mathrm{X}_{1} \mathrm{Z}$ es la interacción entre ambas, $X_{2}$ refiere a las variables de control, y $\varepsilon$ es el término de error de la ecuación. El siguiente esquema grafica la relación propuesta:

Esquema $n^{\circ} 1$

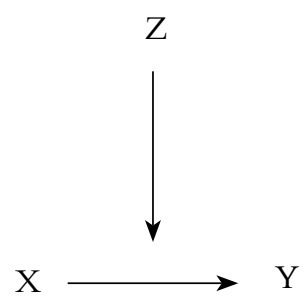

14 Agradezco los valiosos comentarios de Carlos Gervasoni e Iván Llamazares Valdivieso sobre este apartado. 
En el caso de las regresiones lineales, con variable dependiente continua, una de las formas de verificar la existencia de una interacción consiste en monitorear la variación del $\mathrm{R}_{2}$ de la ecuación que contiene la variable interactiva (análisis de efectos moderadores), con respecto a la ecuación que no la contempla (análisis de efectos principales) (Jaccard et al. 1990). Si el agregado de la variable interactiva incrementa el porcentaje de variabilidad del voto oficialista explicado por la ecuación, es decir si hace crecer el $\mathrm{R}_{2}$, $\mathrm{y}$ si ese incremento es estadísticamente significativo ${ }^{15}$, entonces es posible inferir que el contexto político de ese año electoral influyó en la probabilidad de un voto retrospectivo y por lo tanto en la mayor o menor eficacia de la accountability electoral. Las advertencias respecto del uso de interacciones para el caso de las regresiones con variable dependiente dicotómica, como la que se incluye en esta investigación, son sin embargo recurrentes (Jaccard et al. 1990; Brambor et al. 2006; Kenny 2009); en todos los casos se señalan las dificultades que ofrece este tipo de ecuaciones para realizar una correcta interpretación de los resultados. Importa recordar que la presencia de una interacción en una ecuación modifica la interpretación habitual de los coeficientes individuales de cada una de las variables constitutivas de la interacción. Así el coeficiente de $\mathrm{X}_{1}$ indica el impacto de esta variable sobre $\mathrm{Y}$ cuando $\mathrm{Z}$ asume el valor 0 . En el ejemplo concreto de la Tabla $\mathrm{n}^{\circ}$ 4, Ecuación 1, el coeficiente de regresión de Economía $\left(\beta_{1} \mathrm{X}_{1}\right)$ indica el impacto de las Evaluaciones Económicas Retrospectivas sobre la chances de Voto por el Oficialismo $(Y)$, cuando la variable Año $1997(\beta Z)=0$. Dado que esta variable fue recodificada como $1=1997$ y $0=$ Resto de los años del análisis, el 0 corresponde a todos los años distintos de 1997.

15 Aquí se hace referencia al test jerárquico $\mathrm{F}$ que permite medir la presencia de una interacción estadística entre variables. 


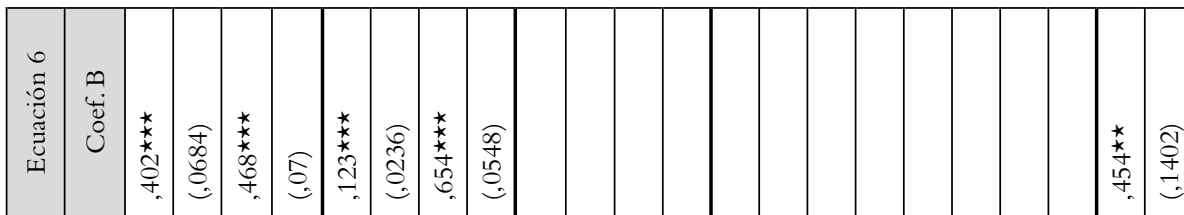

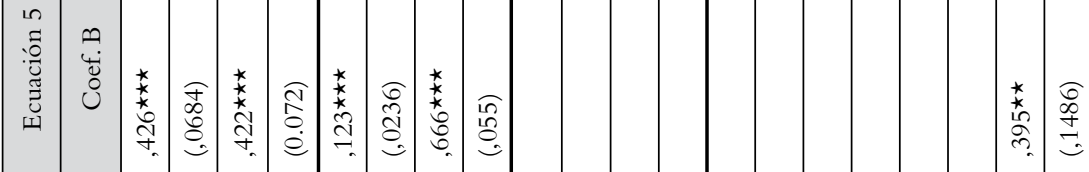

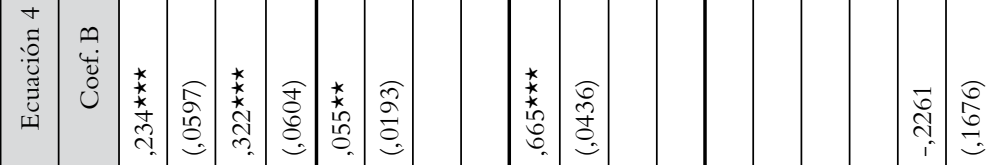

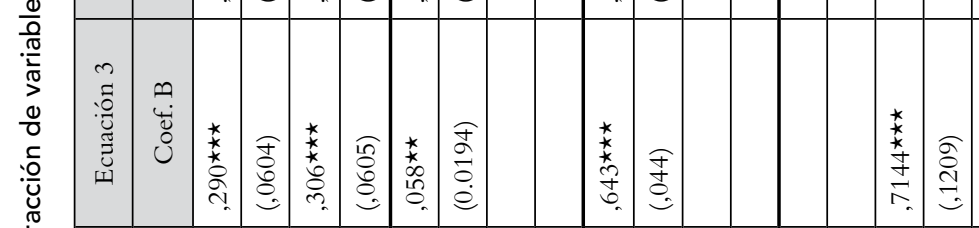

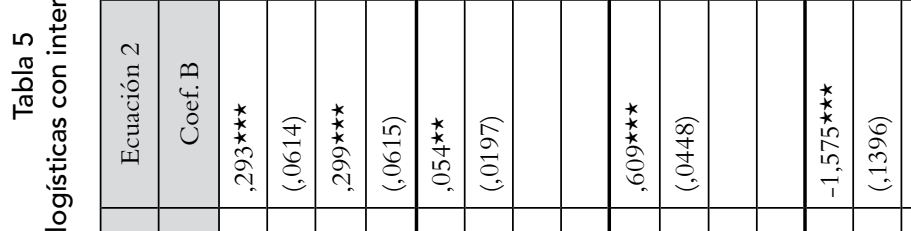

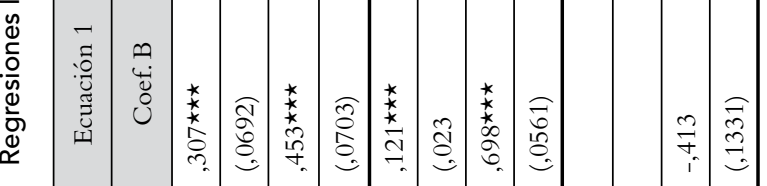




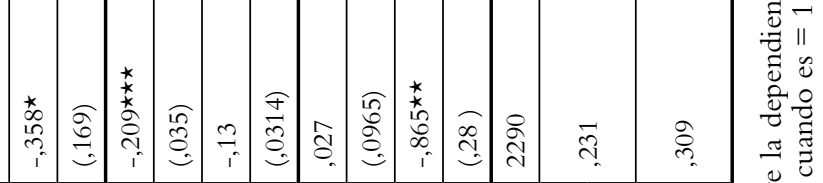

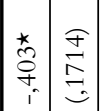

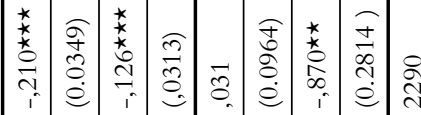

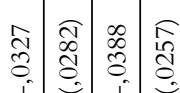

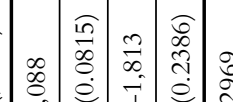

息

栲意

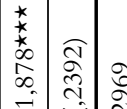

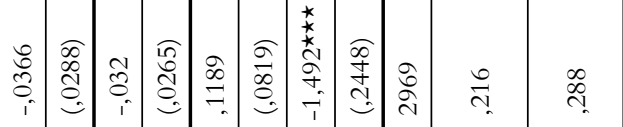

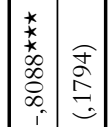

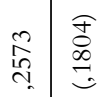

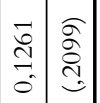

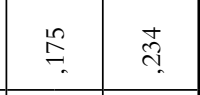

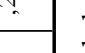

응

苞苛

चू

范

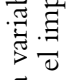

$\because 0$

ำ

금ำ

氜

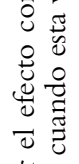

牙究

造

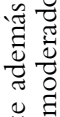

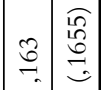

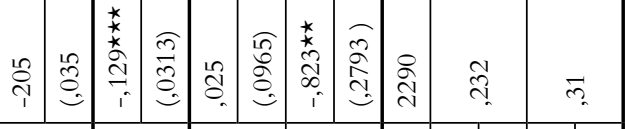

芩艺

离

:

跑芯

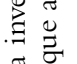

胥范

वี $\frac{5}{5}$

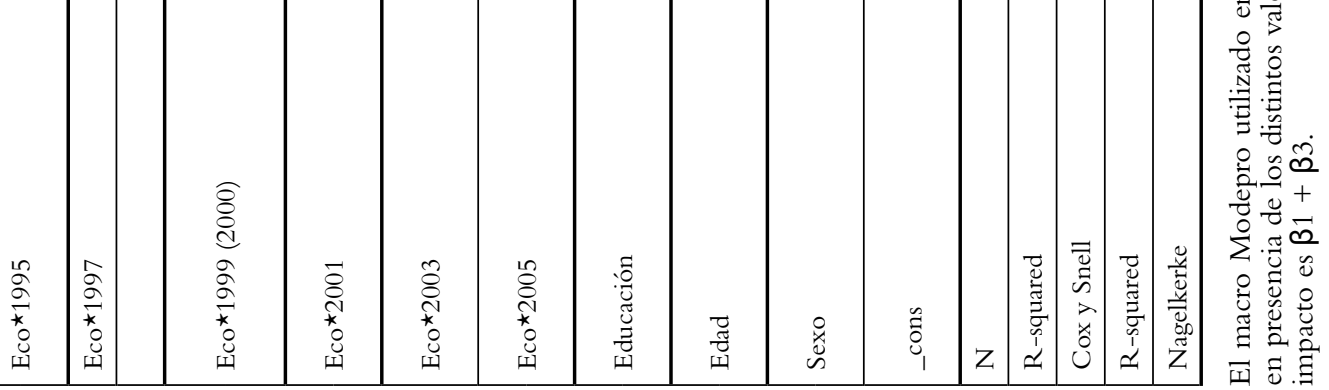


Tabla 6

Test de Efectos

Condicionales de la variable independiente sobre la variable dependiente

\begin{tabular}{|c|c|c|c|c|}
\hline Ecuación 1 & & $\beta$ & se & $p$ \\
\hline $\begin{array}{l}\text { Elección } 1995 \\
\beta 1+\beta 3\end{array}$ & 1 & ,470 & ,153 & ,002 \\
\hline$\beta 1$ & 0 &, 307 & ,069 & ,000 \\
\hline \multicolumn{5}{|l|}{ Ecuación 2} \\
\hline $\begin{array}{l}\text { Elección } 1997 \\
\beta 1+\beta 3\end{array}$ & 1 &,- 515 & ,172 &, 003 \\
\hline$\beta 1$ & 0 & ,293 & ,061 & ,000 \\
\hline \multicolumn{5}{|l|}{ Ecuación 3} \\
\hline $\begin{array}{l}\text { Elección } 1999 \\
\beta 1+\beta 3\end{array}$ & 1 &, 547 & ,172 & ,001 \\
\hline$\beta 1$ & 0 & ,290 & ,060 & ,000 \\
\hline \multicolumn{5}{|l|}{ Ecuación 4} \\
\hline $\begin{array}{l}\text { Elección } 2001 \\
\beta 1+\beta 3\end{array}$ & 1 &, 360 & ,202 & ,075 \\
\hline$\beta 1$ & 0 &, 234 & ,060 & ,000 \\
\hline \multicolumn{5}{|l|}{ Ecuación 5} \\
\hline $\begin{array}{l}\text { Elección } 2003 \\
\beta 1+\beta 3\end{array}$ & 1 & ,023 & ,159 & ,884 \\
\hline$\beta 1$ & 0 & ,425 & ,068 & ,000 \\
\hline \multicolumn{5}{|l|}{ Ecuación 6} \\
\hline $\begin{array}{l}\text { Elección } 2005 \\
\beta 1+\beta 3\end{array}$ & 1 & ,044 & ,158 & ,778 \\
\hline$\beta 1$ & 0 & ,402 & ,068 & ,000 \\
\hline
\end{tabular}

La Tabla $n^{\circ} 5$ presenta el análisis de interacciones. A fin de simplificar la lectura de los datos, se incluyó cada término interactivo, correspondiente a cada uno de los seis años en que se celebraron elecciones, en ecuaciones separadas. Las interacciones resultan significativas para el caso de 1997, 2003 y 2005, a la vez que presentan un signo negativo $\left(-, 809 \star \star \star,-, 403 \star\right.$ y,$- 358^{\star}$ respectivamente). Ello señala que el contexto de esos años influyó negativamente en las chances de un voto de control retrospectivo sobre el gobierno. Específicamente en 1997, considerando dos personas cuyas opiniones económicas retrospectivas difieran en una unidad, el impacto 
de dichas percepciones económicas en el voto fue, 809 menor que en el resto de los años considerados en el análisis (Ecuación 2 de la Tabla 5) ${ }^{16}$. A la vez, el coeficiente positivo y estadísticamente significativo de Economía Retrospectiva indica que una mejora en las evaluaciones económicas aumentó, 293 puntos las chances de apoyo al oficialismo en el resto de los años considerados en el análisis, es decir cuando año $1997=0$.

Los datos del test de N-J contribuyeron a completar el análisis. Continuando con 1997, el coeficiente económico correspondiente al valor 1 de la variable moderadora es negativo y estadísticamente significativo $(\beta=-, 515$ y $\mathrm{p}=, 003$ en la Ecuación 2 de la Tabla $\left.n^{0} 6\right)^{17}$. El mismo indica la magnitud y la dirección del impacto de las percepciones económicas en el voto por el oficialismo para el año 1997. Esto demuestra que, contrariamente a lo postulado por la teoría económica del voto, en 1997 una mejora en las percepciones económicas no aumentó las chances de apoyo al oficialismo. En cuanto al coeficiente 0 de la variable moderadora, el mismo es positivo y estadísticamente significativo $(\beta=, 293 \mathrm{y} p=, 000)$, confirmando las conclusiones ya señaladas para la Tabla $\mathrm{n}^{\circ} 5$.

Del mismo modo, en 2003 y 2005 el impacto de la economía en el voto resultó, 403 y, 358 menor respectivamente que en el resto de los años considerados en el análisis. A la vez, el coeficiente positivo y estadísticamente significativo de Economía Retrospectiva indica que una mejora en las evaluaciones económicas aumentó, 425 y, 402 respectivamente las chances de apoyo al oficialismo en el resto de los años considerados en el análisis, es decir cuando Año 2003 =0 y Año 2005=0 (Ecuaciones 5 y 6 de la Tabla $\left.{ }^{\circ} 5\right)$.

A la vez los coeficientes económicos correspondientes al valor 0 de cada una de las variables moderadoras son estadísticamente significativos $(\beta=, 425 \mathrm{y} p=, 000 \mathrm{y}$ $\beta=, 402$ y $p=, 000$ respectivamente en las Ecuaciones 5 y 6 de la Tabla $\left.n^{\circ} 6\right)$, y mayores que los coeficientes que corresponden al valor 1 de esas variables, los cuales sin embargo no alcanzan significación estadística $(\beta=, 023$ y $\mathrm{p}=, 884$ y $\beta=, 044$ y $\mathrm{p}=, 778$ respectivamente) Esto ratifica por un lado el impacto mayor que tuvo la economía en el voto para los años distintos de 2003 y 2005. Asimismo implica que

Cabe recordar que el coeficiente del término interactivo $\beta_{3}$, refleja lo que hay que sumarle al coeficiente de economía retrospectiva sin interacción $\beta_{1}$ para saber el impacto en el año 1997. En otras palabras, cuando Año 1997 es $=0$ el impacto es $\beta_{1}$, en cambio cuando Año $1997=1$ el impacto es $\beta_{1}+\beta_{3}$.

17 Efectivamente, si se suman las magnitudes de $\beta_{1}+\beta_{3}$, se obtiene el impacto para el año 1997. En este caso, $293+(-, 809)=-, 515$ 
no se pueden extraer inferencias conclusivas respecto de la magnitud de la influencia de la economía en el voto por el oficialismo para 2003 y 2005.

En 1995, 1999 y 2001 en cambio, según surge de la Tabla nº 5, no se verifica tal influjo del contexto político en la relación entre evaluaciones económicas retrospectivas y voto, puesto que los coeficientes de los términos de interacción no alcanzan significación estadística. Es decir, no es posible concluir que el impacto de la economía en el voto haya sido distinto para esos años, respecto del resto considerado en el análisis ${ }^{18}$.

Eso no significa afirmar que la economía no haya impactado en el voto. Ni que el contexto de los años 1995, 1999 y 2001 no haya influido en las chances de apoyo al partido de gobierno. De hecho cuando se analiza el test de la Tabla $n^{\circ} 6$, en la que se puede discriminar el valor del coeficiente económico para los valores 1 y 0 de las variables moderadoras, ambos resultan ser significativos para el caso de las tres elecciones (Ecuaciones 1, 3 y 4). En 1995, 1999 y 2001 efectivamente, las percepciones económicas impactan positivamente en el voto, es decir, hay un voto retrospectivo. Lo que no se verifica es la mediación del impacto del contexto político en esa relación. Considerando a modo de ejemplo la Ecuación 1, tanto para el año 1995 (valor $=1$ de la variable moderadora) como para el resto de los años de la década analizada (valor $=0$ de la misma variable), el impacto de las percepciones económicas en el voto por el gobierno es positivo $(\beta=, 470$ y $p=, 002$ y $\beta=, 307$ y $p=, 000)$. Esto se repite para el año $1999(\beta=, 547 \mathrm{y} \mathrm{p}=, 001 \mathrm{y} \mathrm{b}=, 290 \mathrm{y} \mathrm{p}=, 000)$ y para el año 2001 $(\beta=, 360$ y $p=, 075$ y $\beta=, 234$ y $p=, 000)$.

\section{CONCLUSIONES}

Durante la década transcurrida entre 1995 y 2005 en Argentina, se alternaron tanto gobiernos de derecha como de izquierda. Tuvo lugar una crisis inédita con amplio impacto en el sistema de partidos, que profundizó además el descrédito en las instituciones de gobierno. Se registraron los más altos niveles de volatilidad electoral hasta entonces recordados en elecciones presidenciales. Se incrementó sostenidamente el número efectivo de partidos legislativos y la volatilidad del voto.Y disminuyeron significativamente los niveles de identificación partidaria. Este marco en el que hubo alternancia política, inestabilidad del sistema de partidos, y desafección

18 Se recuerda que el análisis incluye las diez mediciones realizadas a lo largo de la década que transcurre entre 1995 y 2005. 
institucional resulta especialmente desafiante para explorar si las elecciones funcionan o no como un mecanismo de control de los gobiernos.

Los resultados de la investigación confirman la existencia de un voto de control retrospectivo a lo largo de toda la década (Tabla $n^{\circ} 4$ ). Ello implica que los ciudadanos argentinos tomaron en consideración el desempeño económico del gobierno a la hora de decidir su voto. Cuando se analiza en cambio elección por elección se encuentra que, al menos en 1997 y contrariamente a lo postulado por la teoría económica del voto, una mejora en las percepciones económicas no aumentó las chances de apoyo al oficialismo (Tabla $\left.\mathrm{n}^{\circ} 6\right)$.

En cuanto a las evaluaciones económicas prospectivas, éstas tuvieron una mayor influencia que las retrospectivas. Esto es, las expectativas positivas sobre la marcha futura de la situación económica del país presentan una correlación mayor con el voto por el oficialismo, que las evaluaciones favorables acerca del desempeño pasado (Tabla $\left.n^{\circ} 4\right)$. Ello implica que si el votante es optimista respecto del futuro, entonces el oficialismo tiene altas chances de volver a ser apoyado. Dichos datos muestran la necesidad de repensar las relaciones entre evaluaciones pasadas y expectativas futuras, con relación al funcionamiento de la faceta representativa de los gobiernos.

A la vez la confianza en el presidente y la confianza en el gobierno presentaron el mayor impacto en la intención de voto. Esto significa que uno de los componentes básicos de la cultura política (la confianza institucional) demostró mayor poder explicativo que los factores coyunturales (la economía), las predisposiciones de largo plazo (el compromiso religioso y la ideología) y las características socio-demográficas de los votantes (educación, edad y sexo).

Cuando se exploró la influencia del contexto político en el impacto del voto retrospectivo, se encontró variabilidad entre las elecciones. En 1997, 2003 y 2005, el contexto político influyó negativamente en las chances de un voto que tuviera en cuenta la gestión económica del gobierno. En 1995, 1999 y 2001 en cambio, no se verificó tal influjo. Estos resultados ratifican por un lado la influencia de la estructura en el comportamiento individual, y confirman por tanto la necesidad de incluir el análisis del contexto político en el estudio del comportamiento electoral. A la vez recuerdan que el voto es una decisión multidimensional, en la que intervienen además la cultura política, los factores de corto plazo, las predisposiciones de largo plazo y las características socio-demográficas del elector. 
Un estudio longitudinal más extendido en el tiempo permitirá en el futuro analizar la evolución comparada del peso de cada uno de estos factores, a la vez que identificar cuáles variables del contexto político son las que más afectan las chances de un voto de control retrospectivo.

Finalmente, la incipiente mejora a partir de 2002 en la correlación entre percepciones retrospectivas y apoyo al gobierno que mostró el gráfico de curvas (Gráfico ${ }^{\circ}{ }^{6}$ ) deja un interrogante pendiente: ¿impactará la experiencia democrática que acumulen los electores de esta democracias jóvenes, en las probabilidades futuras de tornar a las elecciones un mejor instrumento de rendición de cuentas de los gobiernos?

\section{REFERENCIAS BIBLIOGRÁFICAS}

Alcántara, Manuel (1996). “Elecciones, electores y partidos en América Latina en la década de 1990”. América Latina Hoy.Vol. 13, pp. 7-16.

Alvarez, R.; Nagler, J. (1994). "Voter choice in 1992: economics, issues and anger" California Institute of Technology, Division of the Humanities and Social Sciences, Working Papers: 902.

Anderson, Christopher (1995). Blaming the Government: Citizens and the Economy in five European Democracies. Armonk: Sharpe.

Anderson, Christopher (2000). "Economic Voting and Political Context: a Comparative Perspective”. Electoral Studies 19, pp. 151-170.

Anduiza Perea, Eva (1999). ¿Individuos o sistemas? Las razones de la abstención en Europa Occidental. Madrid: CIS.

Arceneaux, Kevin (2003). “The Conditional Impact of Blame Attribution on the Relationship between Economic Adversity and Turnout”. Political Research Quarterly Vol. 56, No1, pp. $67-75$.

Barreiro, Belén (2004). Explaining the Electoral Performance of Incumbents in Democracies. Madrid: Center Advanced Study Social Sciences.

Barreiro, Belén (2008). "Explaining the Electoral Performance of Incumbents in Democracies”. En Maravall, José M., Sánchez Cuenca, Ignacio (editores), Controlling Goverments. Voters, Institutions and Accountability. USA: Cambridge University Press.

Benton, Allyson (2005) "Dissatisfied Democrats or Retrospective Voters?: Economic Hardship, Political Institutions, and Voting Behavior in Latin America". Comparative Political Studies Vol. 38, N4, pp. 417-442. 
Blais, André y Massicotte, Louis (2002). "Electoral Systems", en Lawrence Le Duc, Richard Niemi, Pippa Norris (editors), Comparing Democracies 2. New Challenges in the Study of Elections and Votin. London: Sage.

Brambor, T.; Clark, W., Golder, M. (2006). "Understanding Interaction Models: Improving Empirical Analyses”. Political Analysis Vol. 14, Nº1, pp. 63-82.

Carey, John; Reynolds, Andrew (2007). "Parties and Accountable Government in New Democracies”. Party Politics Vo. 13, N², pp. 255-274.

Cheibub, José Antonio y Przeworski, Adam (1999). "Democracy, Elections and Accountability for Economic Outcomes”. En Adam Przeworski, Susan Stokes y Bernard Manin (editores), Democracy, Accountability and Representation. New York: Cambridge University Press.

Cheresky, Isidoro; Blanquer, Jean Michel (2003). De la Ilusión Reformista al Descontento Ciudadano. Las Elecciones en Argentina, 1999-2001. Buenos Aires: Homo Sapiens.

Fearon, James (1999). Electoral Accountability and the Control of Politicians: Selecting Good Types versus Sanctioning Poor Performance. En Adam Przeworski, Susan Stokes y Bernard Manin (editores), Democracy, Accountability and Representation. New York: Cambridge University Press.

Fraile Maldonado, Marta (2005). Cuando la Economía Entra en las Urnas. El Voto Económico en España (1979-1996). Madrid: CIS.

Fraile Maldonado, Marta (2007). "La influencia del conocimiento político en las decisiones de voto”. Reis: Revista española de investigaciones sociológicas, $\mathrm{N}^{\circ} 120$, pp. 41-74.

Gèlineau, Francois; Remmer, Karen (2006). "Political Decentralization and Electoral Accountability:The Argentine Experience, 1983-2001”. British Journal of Political Science Vol. 36, Nº1, pp 133-157.

Gèlineau, Francois (2007). "Presidents, Political Context, and Economic Accountability". Political Research Quarterly Vol. 60, N³, pp. 415-428.

Hayes, A. F. \& Matthes, J. (2009). “Computational procedures for probing interactions in OLS and logistic regression: SPSS and SAS implementations”. Behavior Research Methods, Vol. 41, No3, pp. 924-936.

Hellwig, Timothy; Samuels, David (2007). "Electoral Accountability and the Variety of Democratic Regimes”. British Journal of Political Science Vol. 38, N¹, pp. 65-90.

Huckfeldt, Robert; Sprague, John (1993). "Citizens, Contexts and Politics”, en Ada Finifter (editor) Political Science: the State of the Discipline. Washington:American Political Science Association.

Jaccard, J;Turrisi, R. y Wan, C. (1990). Interaction effects in multiple regression. UK: Sage. 
Kinder, Donald; R. Kiewiet; D. Roderick (1979). "Economic Discontent and Political Behavior: The Role of Personal Grievances and Collective Economic Judments in Congressional Voting". American Journal of Political Science. American Journal of Political Science, Vol. 23, No 3. pp. 495-527.

Kinder, Donald; R., Adams, Gordon S.; Gronke, Paul W. (1989). "Economics and Politics in the 1984 American Presidential Election". American Journal of Political Science, Vol. 33, No2, pp. 491-515.

Michael S. Lewis-Beck y Martin Paldam (2000a). "Economic Voting: An Introduction". Electoral Studies Vol. 19, No2-3, pp. 113-121.

Michael S. Lewis-Beck y Richard Nadeau (2000b). "French Electoral Institutions and the Economic Vote”. Electoral Studies Vol. 19, N²-3, pp. 3171-182.

Lijphart, Arendt (1984). Democracies: patterns of Majoritarian and Consensus Government in Twenty-One Countries. New Heaven Yale University Press.

Linz, Juan (1994). "Presidential or Parlamentary Democracy: Does It Make a Difference?" en, Juan Linz y Arturo Valenzuela (compositores), The Failure of Presidential Democracy. Baltimore: Johns Hopkins University Press.

Mainwaring, Scott y Welna, Christopher (2003). Democratic Accountability in Latin America. Oxford: Oxford University Press.

MacKuen, M.; Erikson, R.; Stimson, J. (1992). "Peasants or Bankers? The American Electorate and the U.S. Economy". The American Political Science Review Vol. 86, N³, pp. 597-611.

Manin, Bernard (1998). Los Principios del Gobierno Representativo. Madrid:Alianza.

Maravall, José María (2003). El Control de los Políticos. Madrid:Taurus.

Maravall, José M.; Sánchez Cuenca, Ignacio (2008). Controlling Goverments. Voters, Institutions and Accountability. USA: Cambridge University Press.

Markus, G. (1992). "The Impact of Personal and National Economic Conditions on Presidential Voting, 1956-1988”. American Journal of Political Science. Vol. 36, №3, pp. 829-834.

Murillo, Victoria; Oliveros, Virginia; Vaishnav Milan (2009). "Electoral Revolution or Democratic Alternation". Paper prepared for the XXVIII International Congress Of the LatinAmerican Studies Asocciation, Río de Janeiro.

O’Donnell, Guillermo (2007). Disonancias. Críticas democráticas a la democracia. Buenos Aires: Prometeo.

Paldam, M.; Nannestad, P. (2000). "What do voters know about the economy? A study of Danish data, 1990-1993”. Electoral Studies Vol. 19, N², pp. 363-391. 
Peters, Guy (1999). El Nuevo Institucionalismo. La teoría institucional en ciencia política. Barcelona: Gedisa.

Pitkin, Hanna (1972). The Concept of Representation. Los Angeles: University of California Press.

Powell, Bingham; Whitten, G. (1993). "A Cross-National Analysis of economic voting: taking account of the political context”. American Journal of Political Vol. 37, N², pp. 391-414.

Powell, Bingham Jr. (2000). Elections as Instruments of Democracy. Majoritarian and Proportional Visions. New Heaven \& London:Yale University Press.

Przeworski, Adam (1998). "Democracia y Representación". Revista del CLAD Reforma y Democracia $\mathrm{N}^{\circ} 10$, pp. 7-31.

Przeworski, Adam; Stokes, Susan; Manin, Bernard (1999). Democracy, Accountability and Representation. Cambridge: Cambridge University Press.

Remmer, Karen; Gélineau, Francois (2003). "Subnational Electoral Choice: Economic and Referendum Voting in Argentina, 1983-1999”. Comparative Political Studies Vol. 36, Nº7, pp. 801-821.

Sánchez Cuenca, Ignacio (2008). "How Can Goverments Be Accountable If Voters Vote Ideologically”. En Maravall, José M., Sánchez Cuenca, Ignacio (editors), Controlling Goverments. Voters, Institutions and Accountability, USA: Cambridge University Press.

Samuels, David; Shugart, Matthew (2003). "Presidentialism, Elections and Representation". Journal of Theoretical Politics Vol. 15, N¹, pp. 33-60.

Samuels, David (2004). "Presidentialism and Accountability for the Economy in Comparative Perspective". The American Political Science Review Vol. 98, N³, pp. 425-436.

Tagina, María Laura (2003). "El impacto variable de las percepciones económicas en el voto oficialista". Propuestas para la Sociedad, el Gobierno y la Producción. Buenos Aires: Universidad Nacional de La Matanza.

Tagina, María Laura (2006). "Entre la tradición y la coyuntura: el voto al justicialismo en las elecciones presidenciales de 1995, 1999 y 2003". Trabajo presentado en el 8vo. Congreso Chileno de Ciencia Política, Pensemos la Democracia, Santiago de Chile.

Tagina, María Laura (2008). "El impacto de las actitudes políticas en la responsabilización electoral. Análisis preliminar sobre Argentina y Chile". IV Congreso de la Asociación Latinoamericana de Ciencia Política (ALACIP).

Thurber, James (1991). "Representation, Accountability, and Efficiency in Divided Party Control of Government". Political Science and Politics Vol. 24, Nº 4, pp. 653-657. 


\section{Páginas web}

Atlas Electoral de Andy Tow http://towsa.com/wordpress/

Legislatina, Observatorio del Poder Legislativo en América Latina, Universidad de Salamanca http://americo.usal.es/oir/legislatina/argentina.htm

\section{Observatorio Electoral}

http://www.observatorioelectoral.org/informes/index/navegador.php?country=argentina

Kenny, D., "ModeratorVariables" http://davidakenny.net/cm/moderation.htm

\section{ANEXO}

\section{Fraseo y recodificación de variables}

\section{Intención de Voto:}

¿Por cuál partido votaría este domingo?

Si este domingo hubiera elecciones, ¿por qué partido votaría Ud.?

$1=$ "Partido oficialista"; $0=$ "Resto de los partidos"

En 1995, 1996, 1997 y 1998, 2002, 2003, 2004, 2005:

$1=$ "Partido Justicialista"; $0=$ "Resto de los partidos"

En 2000 y 2001:

$1=$ "Alianza UCR- Fre.Pa.So + Unión Cívica Radical +Frente País Solidario"; $0=$ "Resto de los partidos"

\section{Economía País Retrospectiva:}

(1995-1997-2000) ¿Considera Ud. que la situación económica actual del país es mejor, igual o peor que hace doce meses?

(2001-2003-2005) ¿Considera Ud. que la situación económica actual del país está mucho mejor, un poco mejor, casi igual, un poco peor o mucho peor que hace doce meses?

-1 = "peor"; 0 = "igual”; $1=$ "mejor" 


\section{Economía País Prospectiva:}

¿Y en los próximos 12 meses cree Ud. que, en general, la situación económica del país será mejor, igual o peor que ahora?

¿Y en los próximos 12 meses cree Ud. que, en general, la situación económica del país será mucho mejor, un poco mejor, igual un poco peor o mucho peor que ahora?

¿Y en los próximos 12 meses cree Ud. que, en general, la situación económica del país será mucho mejor, un poco mejor, casi igual un poco peor o mucho peor que ahora?

-1 = "peor"; 0 = "igual"; $1=$ "mejor"

\section{Ideología:}

En política se habla normalmente de izquierda y derecha. En una escala donde 0 es la izquierda y 10 la derecha. ¿Dónde se ubicaría Ud.?

\section{Compromiso Religioso:}

¿Cómo se considera Ud.? Muy practicante, Practicante, No muy practicante, No practicante.

$1=$ "No practicante"; $2=$ "No muy practicante"; 3= "Practicante"; 4= "Muy practicante"

\section{Confianza Presidente, Confianza Gobierno, Confianza Congreso:}

Por favor, mire esta tarjeta y dígame, para cada uno de los grupos, instituciones o personas mencionadas en la lista, ¿cuánta confianza tiene Ud. en...? ¿Diría que tiene mucha, algo, poca o ninguna confianza en...?

$1=$ "Ninguna confianza"; $2=$ "Poca confianza"; $3=$ "Algo de confianza"; $4=$ "Mucha confianza" 


\section{Confianza Interpersonal:}

Hablando en general, ¿diría Ud. que se puede confiar en la mayoría de las personas o que uno nunca es lo suficientemente cuidadoso en el trato con los demás?

$1=$ "Uno nunca es lo suficientemente cuidadoso"; $2=$ "Se puede confiar en la mayoría de las personas"

\section{Educación:}

1= "Analfabeto"; 2= "Básica incompleta"; 3= "Básica completa"; 4=”Secundaria, media, técnica incompleta"; $5=$ "Secundaria, media, técnica completa"; 6= "Superior incompleta"; $7=$ "Superior completa".

\section{Edad (años cumplidos):}

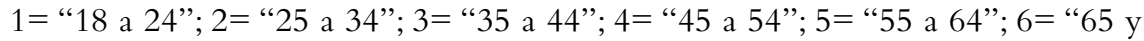
más"

\section{Sexo:}

$1=$ "mujer"; $0=$ "hombre" 